\title{
Linguística experimental: aferindo o curso temporal e a profundidade do processamento
}

\author{
Experimental Linguistics: \\ measuring the time course and the depth of processing
}

\section{Marcus Maia Universidade Federal do Rio de Janeiro/CNPq}

\section{Resumo}

Discute-se, neste artigo, a aferição do curso temporal da computação dos subprocessos gramaticais e a avaliação da sua profundidade, nas três dimensões envolvidas necessariamente no estudo do processamento, a saber, os sujeitos, os métodos e o input linguístico. A inspeção sistemática do curso temporal do processamento de diferentes estruturas tem revelado que muitos subprocessos linguísticos são, frequentemente, subespecificados ou mesmo não especificados. O presente artigo investiga discrepâncias na aferição on-line e off-line de construções estruturalmente ambíguas em português, envolvendo os princípios da Aposição Mínima e da Aposição Local (cf. FRAZIER; 1979; FRAZIER; RAYNER, 1982), para demonstrar que, ao contrário do processo de análise sintática, que é imediato, a informação de natureza pragmática (plausibilidade) e lexical (subcategorização e traços [+humano/-humano]) é acessada tardiamente. Discrepâncias relacionadas aos grupos de sujeitos são também demonstradas no julgamento de ilhas sintáticas e discrepâncias relacionadas ao efeito goodenough (cf. FERREIRA et al., 2002) com diferentes tipos de input linguístico são analisadas em estudos de rastreamento ocular.

Palavras-chave

Linguística Experimental, Processamento de frases, Teoria do Garden-Path, Curso temporal, Profundidade do processamento, Rastreamento ocular. 


\section{Abstract}

This paper discusses the time course and the depth of the computation of the grammatical sub-processes along the three dimensions which are necessarily involved in the study of language comprehension, namely, the subjects, the methods and the linguistic input. The systematic inspection of the time course of processing of different linguistic structures has revealed that many sub-processes are often underspecified or even nonspecified. This study investigates discrepancies between on-line and off-line measures in the research of structurally ambiguous sentences in Brazilian Portuguese, involving the Late Closure and the Minimal Attachment Principles (cf. FRAZIER; 1979; FRAZIER; RAYNER, 1982), in order to demonstrate that, unlike the syntactic parsing process, which is immediate, access to pragmatic (plausibility) and lexical (subcategorization and [+human/human] features) information is not so early. Discrepancies related to the factor "group of subjects" is also demonstrated in the judgment of syntactic islands and discrepancies related to the "good-enough effect" (cf. FERREIRA et al., 2002) with different types of linguistic input also analyzed based on eye-tracking studies.

\section{Keywords}

Experimental Linguistics, Sentence processing, Garden-Path Theory, Time course, Depth of processing, Eye-tracking. 


\section{Introdução}

A revolução cognitivista da metade do século 20 (cf. GARDNER, 1985) permitiu que as línguas humanas passassem a ser estudadas sistematicamente como processos cognitivos. Utilizando julgamentos intuitivos informais de aceitabilidade ou de gramaticalidade de frases, a Linguística Gerativa pôde operar essa importante mudança no foco dos estudos linguísticos, que deixaram de limitar-se à análise exaustiva dos corpora, realizada no âmbito das correntes estruturalistas, para desenvolverem a modelagem dos processos cognitivos subjacentes ao conhecimento da linguagem. Inegavelmente, os julgamentos intuitivos informais constituíram a principal metodologia de pesquisa no âmbito da linguística gerativa por várias décadas, balizando o ponto de partida e o ponto de chegada das análises. Desde há muito, no entanto, diversos autores vêm questionando a confiabilidade dos dados informais de julgamento (cf. HILL, 1961; LABOV, 1996; SCHÜTZE, 1996; COWART, 1997; KITAGAWA; FODOR, 2006; FEATHERSTON, 2007; PHILLIPS, 2009; GIBSON; FEDORENKO, 2010, entre muitos trabalhos), apontando a sua instabilidade e consequente não confiabilidade, pelo menos como ponto de chegada das análises.

Por essa razão, duas novas especialidades linguísticas vêm emergindo há alguns anos, chamadas, respectivamente, Sintaxe Experimental e Semântica Experimental, que adotam criteriosamente o método experimental, já usado em Psicolinguística há muitas décadas, não só procurando garantir evidências mais precisas e seguras para a constituição da teoria linguística como também permitindo refinar o diálogo entre o estudo da competência e o estudo do desempenho da linguagem.

O presente artigo pretende revisar estudos desenvolvidos sobre a compreensão de frases em português, no âmbito do Laboratório de Psicolinguística Experimental - LAPEX (UFRJ / CNPq), envolvendo questões sintáticas e semânticas, utilizando metodologias cronométricas on-line, tais como as técnicas de leitura / audição automonitoradas e de rastreamento ocular, que permitem acessar o curso temporal do processamento em milésimos de segundos, sendo, portanto, 
aptas a identificar a influência de fatores estruturais, semânticos e contextuais na compreensão de palavras e frases. Essas metodologias teriam, por isso mesmo, o potencial de contribuir para questões centrais sobre a arquitetura da gramática, avaliando e comparando modelos teóricos em termos de sua realidade psicológica.

Os modelos de representação gramatical têm se dividido entre propostas de arquitetura lexicalistas e construcionistas. Os modelos lexicalistas (cf. CHOMSKY, 1995), embora admitindo unidades menores do que a palavra, consideram a palavra pronta como sendo a unidade que dá entrada na derivação sintática, ao passo que modelos não lexicalistas, como a Morfologia Distribuída (cf. HALLE; MARANTZ, 1993), por exemplo, assumem uma computação sintática operando já no nível sublexical.

A área da Psicolinguística conhecida como Processamento de Frases (Sentence Processing), igualmente, tem sido caracterizada pela oposição entre duas classes de modelos incompatíveis. De um lado, modelos baseados no paradigma simbólico, tal como a Teoria do Garden Path - TGP (cf. FRAZIER; FODOR, 1978; FRAZIER, 1979; FRAZIER; RAYNER, 1982), que assume um processador em dois estágios (parsing e interpretação), propõem uma análise sintática inicial, serial e incrementacional, baseada em métricas de simplicidade, atrasando o acesso a informações semânticas e pragmáticas para a fase interpretativa, pós-sintática. De outro lado, modelos conexionistas, baseados no paradigma de redes (cf. MACDONALD; PEARLMUTTER; SEIDENBERG, 1994; TRUESWELL; TANENHAUS; GARNSEY, 1994; TRUESWELL; TANENHAUS; KELLO, 1993), propõem que o processador ativa em paralelo múltiplas fontes de informação que podem competir entre si, produzindo ativações com diferentes pesos.

Em contraste, conforme revisamos em Maia e Finger (2005), a TGP propõe como postulados fundamentais que: (1) há um processador sintático autônomo ou parser, que usa uma porção do seu conhecimento gramatical isolado do conhecimento de mundo e outras informações para a identificação inicial das relações sintagmáticas; (2) o parser confronta-se com sintagmas de aposição ambígua e compromete-se com uma estrutura única; (3) pressionado pelo sistema de memória de curto prazo, que tem um limite estreito de computação e armazenamento, o parser segue princípios psicológicos de minimalidade e de localidade na escolha dessa estrutura preferencial: use o menor número possível de nós (Princípio da Aposição Mínima) e, se duas aposições mínimas existem, aponha cada nova palavra ao sintagma corrente (Princípio da Aposição Local). 
No âmbito dessa classe de modelos, conforme discutido em Sanford e Stuart (2002), geralmente supõe-se que os subprocessos modulares, que analisam o input linguístico, na compreensão, sejam plenamente articulados, não só iniciando rapidamente mas também completando-se de modo rápido e pleno. Nesse sentido, a verificação do curso temporal em que esses processos ocorrem tem tido implicações importantes para o estabelecimento da arquitetura dos sistemas de representação e de compreensão da linguagem, permitindo trazer para o domínio empírico a análise dos processos de representação e acesso dos diferentes subconhecimentos que compõem a faculdade humana de linguagem que, segundo Chomsky (1995, p. 2), seria composta, justamente, por um sistema cognitivo de representação do conhecimento e por um sistema de desempenho, que acessa e utiliza a informação linguística.

Conforme discutido em Phillips, Wagers e Lau (2011), a pesquisa sobre a implementação on-line das condições estruturais de representação tem produzido um "perfil desigual" (uneven profile), no sentido de que algumas condições gramaticais parecem ser mais diretamente implementáveis no processamento do que outras, o que indicaria, segundo Phillips, Wagers e Lau (2011), a existência do que os autores denominam de "falibilidade seletiva", decorrente de "ilusões gramaticais". A identificação mais precisa desses processos, conforme apontam os autores, é condição fundamental para a postulação de modelos teóricos de representação e de processamento da linguagem.

No presente artigo, revisamos trabalhos em que a relação entre os níveis de representação e de processamento do conhecimento linguístico são testados, em Português, no que diz respeito ao acesso a esses sistemas durante a compreensão on-line de frases em português, utilizando, como dissemos, metodologias cronométricas, que permitem capturar e analisar os processos computacionais no momento mesmo em que estes estão ocorrendo. Pesquisa dessa natureza já vem sendo desenvolvida em nosso laboratório (Laboratório de Psicolinguística Experimental - LAPEX / UFRJ) há cerca de quinze anos, com resultados regulares, oferecidos na forma de apresentações em congressos nacionais e internacionais, artigos em periódicos, capítulos de livros, além de um total de 15 dissertações de mestrado e 10 teses de doutorado orientadas ou coorientadas, na área de Processamento da Linguagem.

Ao longo desses anos de pesquisa, pudemos estabelecer, com clareza, a questão que constitui, hoje, um dos temas centrais do programa de investigação do laboratório: a aferição do curso temporal dos subprocessos gramaticais, bem como a avaliação da sua profundidade, nas três dimensões envolvidas necessa- 
riamente no estudo do processamento, a saber, os sujeitos, os métodos e o input linguístico. A inspeção sistemática do curso temporal do processamento tem revelado que muitos subprocessos linguísticos são, frequentemente, subespecificados ou mesmo não especificados. Portanto, muito distante do que se poderia supor sobre um "falante ouvinte-ideal", no laboratório, descobre-se, na verdade, que a profundidade do processamento parece ser variável em função de fatores que precisam ser investigados com profundidade para serem mais claramente identificados e controlados. De um lado, há fatores diretamente relacionados aos sujeitos e às técnicas e tarefas experimentais. De outro lado, há propriedades estruturais do próprio input, que podem apresentar graus variados de especificação, cuja investigação é de particular interesse para o estabelecimento de análises mais confiáveis sobre a arquitetura dos subconhecimentos linguísticos.

$\mathrm{O}$ artigo se organiza da seguinte forma. Nas primeiras duas subseções da seção 2, resenhamos estudos sobre a compreensão de sintagmas preposicionais estruturalmente ambíguos, que são investigados por meio de diferentes técnicas e tarefas experimentais, com aferição on-line e off-line (questionários, leitura automonitorada, rastreamento ocular), procurando-se demonstrar que o processo de estruturação dessas frases (parsing) guia-se por algoritmos sintáticos de especificação imediata, enquanto que a informação sobre a pressuposição pragmática, bem como a informação de natureza lexical, sobre a grade de subcategorização dos verbos, parece estar disponível apenas em fases posteriores, pós-sintáticas, da análise. Na subseção final da seção 2, revisamos estudo de Barile e Maia (2008), para demonstrar efeitos diferenciados entre grupos de sujeitos realizando a mesma tarefa de julgamento imediato de gramaticalidade. Finalmente, na seção 3, consideramos um caso interessante de discrepância na interpretação de frases em que ocorrem garden-paths. Na seção 3.1, apresentamos o estudo de rastreamento ocular de Ribeiro (2012) sobre o processamento de orações com ambiguidade local e temporária, envolvendo o Princípio da Aposição Local. Na seção 3.2, focalizamos o Princípio da Aposição Mínima, revisando, inicialmente, um dos estudos de leitura automonitorada, apresentado originalmente em Maia et alii (2003), em que se observa o efeito garden-path on-line com estruturas ambíguas do tipo "verbo principal / relativa reduzida" (main verb / reduced relative), mas não se identifica acesso imediato à informação semântica do traço [+humano/humano]. Em seguida, reportamos um estudo de rastreamento ocular, ainda não publicado, sobre orações estruturalmente ambíguas do mesmo tipo, também envolvendo o Princípio da Aposição Mínima. Comparam-se, então, os dois estudos de rastreamento ocular, sugerindo-se que a discrepância encontrada nos padrões 
de interpretação dos dois tipos de estrutura estaria relacionada a diferenças na intensidade do efeito garden-path provocado por cada um dos dois tipos de input. A seção 4 apresenta as considerações finais do artigo.

\section{Curso temporal e especificação da informação no processamento: efeitos de técnicas on-line e off-line e efeitos de grupos de sujeitos}

\subsection{Acesso à informação estrutural e contextual no processamento de Sintagmas Preposicionais}

Em um estudo de 2003, Maia e alunos procuraram estabelecer, inicialmente, por meio de questionários, qual seria a preferência de interpretação de um tipo de ambiguidade de aposição sintática, clássica na literatura, ${ }^{1}$ como a frase exemplificada abaixo, em que a gramática permite tanto a aposição do SP como adjunto adverbial quanto como adjunto adnominal do SN objeto, o turista:

O menino viu o turista com o binóculo.

Maia et alii (2003) também procurou verificar se a preferência por cada uma das duas análises possíveis poderia ser influenciada por um contexto prévio que, manipulando pressuposições pragmáticas, tornasse mais ou menos plausível a aposição do SP ao SN. Assim, apresentaram-se a 40 alunos de graduação da UFRJ duas versões de questionários, contendo 20 frases experimentais, como as exemplificadas abaixo, distribuídas em quadrado latino, entre 40 frases distratoras:

\section{QUADRO 1 \\ Estudo de Questionário}

\section{1a - Contexto -Plausível:}

Havia um turista no parque. 0 policial viu 0 turista com 0 binóculo.

1b - Contexto + Plausível:

Havia dois turistas no parque. 0 policial viu o turista com 0 binóculo. Quem estava com o binóculo?

O contexto -Plausível, exemplificado em (1a), menciona um referente único, enquanto que o contexto +Plausível, em (1b), menciona dois referentes, pretendendo aumentar a plausibilidade de se restringir pela aposição do SP ao $\mathrm{SN}$, o universo dos referentes possíveis sobre o qual se faz a afirmação contida 
na frase. Os resultados do questionário são apresentados na TAB. 1, abaixo, em que se computam as respostas dadas às perguntas, quantificando-se as preferências interpretativas pela aposição do SP ao SV (aposição alta) ou ao SN (aposição baixa), cruzando-as com o contexto + /-plausível.

TABELA 1

Resultados e percentuais por condição experimental

\begin{tabular}{|l|l|l|}
\hline Plausibilidade & SP de SV & SP de SN \\
\hline -Plausível & $259 / 64,9 \%$ & $141 / 35,1 \%$ \\
\hline +Plausível & $219 / 54,9 \%$ & $181 / 45,1 \%$ \\
\hline
\end{tabular}

Observe-se que, mesmo no contexto mais plausível, não há preferência maior do que $50 \%$ pelo $\mathrm{SN}(\mathrm{N}=-1,91, \mathrm{p}<0,05)$. De toda forma, o contexto teve forte influência sobre as respostas: no contexto mais plausível houve um aumento significativo da proporção de preferência pela aposição ao $\mathrm{SN}(\mathrm{t}(399)=2,90 ; \mathrm{p}$ $<0,01)$. Na condição mais plausível, há diferenças menos acentuadas em favor da aposição alta, computando-se número significativamente maior de aposições baixas, o que indica uma interação entre a manipulação do número de referentes no contexto anterior e a escolha da aposição baixa do SP, especificando o SN. Entretanto, em um estudo de questionário, restrito à aferição de avaliação interpretativa necessariamente posterior ao processo de análise da frase, naturalmente, nada se pode saber sobre o curso temporal do processo de compreensão em si mesmo.

Embora haja se registrado uma interação significativa entre a informação sobre o número de referentes no contexto discursivo e a decisão de aposição sintática do sintagma preposicional, essa diferença na interpretação do SP poderia estar refletindo uma decisão de reanálise do processador, já que não se monitorou o processamento on-line da frase. Em outras palavras, o processador poderia haver se comprometido rapidamente com a aposição mínima, apondo o SP ao SV, evitando, assim, o SN complexo. Em um segundo passe, no entanto, antes de escrever a sua resposta, o leitor reanalisaria a decisão inicial, considerando, então, o fator 
pragmático, ou seja, a existência de mais de um referente possível no discurso tornaria mais plausível restringir-se o referente do SN, especificando-o pela aposição do SP.

Com o objetivo de se verificar se esse efeito registrado no estudo de questionário poderia também ser identificado já na fase inicial do parsing sintático, realizou-se, em seguida, um experimento on-line de leitura automonitorada, que registra os tempos médios de leitura das partes em que se dividem as frases, permitindo que se entretenham hipóteses acerca do curso temporal do processamento.

Projetou-se um experimento de leitura automonitorada, em que 24 sujeitos foram solicitados a ler, da forma mais natural e rápida, duas orações segmentadas, conforme indicado pelas barras oblíquas, nos exemplos abaixo. Cada sujeito foi exposto a 16 frases experimentais, apresentadas randomicamente com 32 distratoras, totalizando 48 frases. As frases experimentais distribuíam-se em quatro condições, a saber, +PB (+plausível baixa), +PA (+plausível alta), -PB (-plausível baixa) e -PA (-plausível alta).

\section{QUADRO 2 \\ Exemplos dos materiais do estudo de leitura automonitorada}

(2a) +PB: Havia dois turistas no parque. / O policial/viu o turista /com a ferida aberta. (2b) +PA: Havia dois turistas no parque. / O policial / viu o turista /com o binóculo preto. (2c) -PB: Havia um turista no parque. / O policial / viu o turista / com a ferida aberta. (2d) -PA: Havia um turista no parque. / O policial / viu o turista / com o binóculo preto.

Após a leitura de cada frase, cujos segmentos eram apresentados de maneira não cumulativa, pressionando-se a tecla amarela na caixa de botões acoplada ao computador Macintosh, seguia-se uma pergunta interpretativa sobre a frase, que devia ser respondida pressionando-se a tecla verde ( $\mathrm{sim}$ ) ou a tecla vermelha (não) na caixa de botões. O experimento pretendeu testar duas hipóteses: (a) o Princípio da Aposição Mínima, que prediz a preferência imediata pela aposição alta do SP; (b) a interferência de fatores não estruturais, tal como a pressuposição pragmática, no processamento on-line. A hipótese (a) seria confirmada caso a leitura do SP, apresentado no segmento 4 de cada frase experimental, fosse mais lenta nas condições em que se forçava uma leitura baixa (+PB e -PB) do que nas condições onde a aposição alta (+PA e -PA) era possível. 
Isso deveria ocorrer, pois, sendo operativo em português, o Princípio da Aposição Mínima determinaria que a aposição do SP fosse feita inicialmente, como default, ao SV, computando-se o SN simples. Comprometendo-se inicialmente com essa análise, o leitor entraria em um garden-path nas frases em que se forçava a leitura baixa, precisando, então, rever a sua análise inicial. Tanto o efeito surpresa ao encontrar-se no garden-path quanto a revisão da decisão de aposição sintática inicial requereriam mais operações mentais do que as que seriam necessárias para processar as frases em que a aposição alta do SP era admitida, determinando o maior tempo de leitura dos SPs nas condições baixas. A hipótese (b) seria confirmada caso se detectasse diferenças significativas nos tempos de leitura dos SPs entre as condições +P e -P. Por exemplo, os SPs na condição -PB deveriam registrar tempos médios de leitura mais elevados do que os SPs na condição $+\mathrm{PB}$, se a pista sobre a pressuposição referencial fosse levada em conta rapidamente, assim como parece ter ocorrido na tarefa off-line.

Como se pode comprovar, observando o gráfico abaixo, que indica os tempos médios de leitura dos segmentos críticos (segmento 4) para cada condição, o experimento demonstrou que o Princípio da Aposição Mínima é operativo também nesse tipo de estrutura ambígua em português. $\mathrm{O}$ experimento demonstrou ainda não haver interação significativa entre a informação relativa à pressuposição pragmática e a aposição sintática preferencial do SP. Note-se que as condições em que se forçou a aposição baixa apresentam os tempos de leitura mais altos, conforme predito. Os cruzamentos - PA x - PB apresentaram diferenças significativas, assim como os cruzamentos $+\mathrm{PA} \mathrm{x}+\mathrm{PB}$. Também o cruzamento de PA $(+\mathrm{PA}$ e $-\mathrm{PA})$ e $\mathrm{PB}(+\mathrm{PB}$ e $-\mathrm{PB})$ revelou-se significativo, indicando um efeito principal da interação entre a aposição alta ou baixa do SP e os tempos de leitura, indicativo do efeito garden-path e da reanálise, conforme predito. Já os cruzamentos $-\mathrm{P} x+\mathrm{P}$ não são significativos, nem com relação ao cruzamento de $-\mathrm{PA} x+\mathrm{PA}(\mathrm{p}=0,8505)$, nem com relação ao cruzamento de $-\mathrm{PB} x+\mathrm{PB}(\mathrm{p}=0,1244)$. 


\section{GRÁFICO 1}

Tempos médios de leitura do segmento crítico (segmento 4)

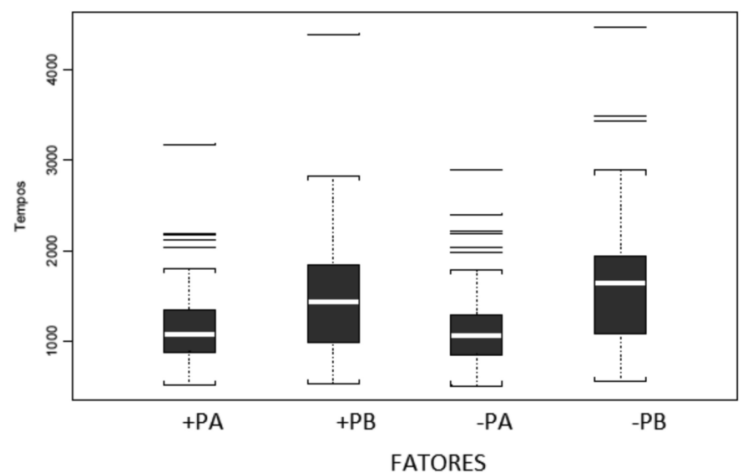

O GRAF. 1 sugere que as frases com B (aposição baixa) têm tempos médios de leitura maiores. Uma ANOVA com um fator (cujos níveis eram os tipos de frases) mostrou um resultado significativo $(\mathrm{F}(3,355)=18,03, \mathrm{p}=0)$. Isso significa que há diferenças nos tempos de leituras para cada tipo de frase. Como as frases com B (aposição baixa) apresentam um tempo de leitura maior do que as frases com A (aposição alta), examinou-se o tempo de leitura, considerando o fator com os níveis A e B, utilizando uma ANOVA 2x2. Os resultados da análise com A vs. B e plausibilidade como fatores within subject mostraram um efeito principal de $\mathrm{A} v s$. B de $(\mathrm{F}(1,356)=49,62, \mathrm{p}=0)$ com as frases $\mathrm{A}(1148,6 \mathrm{~ms})$ apresentando um tempo de leitura significativamente menor do que as frases B $(1563,7 \mathrm{~ms})$. O efeito principal de plausibilidade, em contraste, não apresentou um resultado estatisticamente significativo $(\mathrm{F}(1,356)=1,61, \mathrm{p}=0,21)$.

Esses resultados indicam que o efeito de pressuposição pragmática obtido no experimento off-line não ocorreu no parsing sintático, mas apenas na fase interpretativa da compreensão, sendo o parsing impermeável a esse tipo de informação não estrutural.

\subsection{Processamento de Sintagmas Preposicionais Adjuntos e Argumentos}

Em Maia (2008) e Maia (2010), apresentam-se resultados de estudos de leitura e audição automonitoradas e de rastreamento ocular de frases contendo 
sintagmas preposicionais (SP) com função de adjunto ou de argumento de um verbo, que admitem aposição sintática ambígua ao sintagma verbal ou ao sintagma nominal objeto. Os resultados obtidos no monitoramento da leitura de frases como (3) e (4) indicam que o processador sintático não faz uso imediato da informação lexical relativa ao estatuto do SP como adjunto ou argumento, acessando essa informação apenas na fase de reanálise, após a recuperação do efeito labirinto (garden-path).

(3) O redator escreveu o manual para o professor para o editor da nova série.

(4) O contador enviou a carta para o professor para o diretor da faculdade.

O primeiro SP em cada frase (para o professor) é temporariamente ambíguo entre uma aposição ao SV ou ao SN objeto. Segundo o Princípio da Aposição Mínima (Minimal Attachment), estabelecido em Frazier (1979) e Frazier e Rayner (1982), no âmbito da Teoria do Garden-Path, a preferência default de resolução de ambiguidades desse tipo seria pela aposição ao SV, evitando a formação de SNs complexos. Comprometendo-se rapidamente com essa análise mínima, ao encontrar o segundo SP na frase (para o editor / para o diretor), os leitores tipicamente entram em garden-path, ou seja, não tem como integrar esse SP à frase que estão processando. Precisam, então, retroceder e revisar a análise com que se comprometeram inicialmente, diagnosticando e remediando o garden-path (cf. FODOR; INOUE, 1994): o primeiro SP é aposto, agora, ao SN, liberando a aposição do segundo SP ao SV. O que é interessante observar-se, no entanto, é que esse mesmo padrão de leitura ocorre quer se trate de um verbo ditransitivo, que subcategoriza obrigatoriamente um SP argumento, como é o caso do verbo enviar, quer se trate de um verbo monotransitivo como escrever, em que o SP não subcategorizado é apenas um adjunto opcional. Como identificado em Maia (2008), embora apenas enviar subcategorize um SP, a frase com o verbo escrever também causa garden-path da mesma proporção nos leitores, ou seja, não parece que haja uma inspeção da informação lexical relativa à grade de subcategorização, a tempo de influenciar a análise sintática inicial da frase. Em Maia (2010), reporta-se estudo de rastreamento ocular que comprova que a informação sobre a grade de subcategorização do verbo não estaria, de fato, especificada para o parser na primeira passagem do olhar. O parser segue adiante sem levá-la em conta, precisando revisar sua análise, posteriormente. É justamente no curso desse processo de revisão, na fase de releitura das frases, entretanto, que se encontram diferenças entre as duas grades de subcategorização: os índices de movimentos sacádicos 
regressivos e os tempos médios de fixação regressiva são significativamente maiores na região do verbo "enviar" do que na região do verbo "escrever", sugerindo que a reanálise de um verbo bitransitivo é mais custosa do que a reanálise de um verbo monotransitivo.

Por outro lado, Maia (2008) discute resultados de teste off-line, com base em questionários, que indicavam especificação do estatuto do SP como adjunto ou argumento, registrando-se preferências significativas por SPs argumentos sobre os adjuntos, tanto em aposição a SNs quanto a SVs. A análise com base em métodos on-line, ao contrário daquela realizada a partir de resultados off-line difere, portanto, de modo interessante no que se refere à especificação do estatuto adjunto / argumento dos SPs. Uma decisão imediata não especificada do processador sintático (parser) precisa ser reanalisada, em um contexto garden-path específico, sendo o resultado off-line em si mesmo incapaz de revelar os procedimentos de análise inicial não especificada, que é revista, em um segundo momento da análise.

Parece, portanto, claro que, apenas com a metodologia cronométrica adequada, é que se pode investigar apropriadamente essa importante questão de arquitetura cognitiva, uma vez que, como verificamos nos estudos de aposição de SPs em português, a metodologia não cronométrica poderia indicar especificação em favor do SP argumento, quando, de fato, essa especificação não é o default, conforme afere-se por meio de estudos cronométricos, somente sendo estabelecida a posteriori, em função de outros fatores.

Em outros experimentos realizados no LAPEX, encontramos, igualmente, diferenças relacionadas à especificação da informação estrutural no processamento. Em um desses estudos, reportado em 2.3, as diferenças encontradas no julgamento de ilhas sintáticas são decorrentes não de diferenças entre as técnicas de aferição on-line ou off-line, como nos casos reportados em 2.1 e 2.2, mas das diferenças entre os dois grupos de sujeitos, realizando a mesma tarefa com as mesmas técnicas de aferição, incluídos em um design fatorial em que se controlava o conhecimento prévio de cada grupo em relação à existência das ilhas sintáticas.

\subsection{Julgamento de ilhas sintáticas}

Como lembramos na introdução, os questionamentos sobre a informalidade e, principalmente, sobre a instabilidade dos julgamentos de aceitabilidade / gramaticalidade são frequentes e antigos. Há trabalhos indicando convincentemente que os julgamentos não são necessariamente do tipo "tudo ou nada", mas, frequentemente, apresentam gradiência (cf. COWART, 1997; FEATHERSTON, 
2007, entre vários outros). Por outro lado, Snyder (2000) demonstra experimentalmente a chamada "doença do linguista" ou efeito de saciação no julgamento de gramaticalidade de sentenças. De fato, muitos linguistas reportam que frases que são inicialmente julgadas como agramaticais tendem a se tornar cada vez mais aceitáveis uma vez que se continua a considerá-las, passando a ser citadas como agramaticais apenas por força do hábito ou porque sua agramaticalidade se tornou padrão na literatura teórica. Em seu experimento, Snyder apresentou a 22 alunos de graduação do Massachusetts Institute of Technology um questionário contendo frases com ilhas sintáticas, para julgamento. Os sujeitos deviam marcar Sim / Não após verem 50 frases em contexto, distribuídas em blocos. Considerava-se a existência de saciação se o número de julgamentos positivos nos dois últimos blocos superasse significativamente o número de julgamentos positivos nos dois primeiros blocos. De fato, as conclusões do estudo indicaram a existência de efeitos de saciação significativa para vários tipos de ilhas sintáticas.

Manipulando o fator grupo de sujeitos, em vez da apresentação dos materiais, Barile e Maia (2008) também demonstraram a existência do efeito de saciação no julgamento de ilhas sintáticas em português. Os autores apresentaram para julgamento, na tela de um computador, os mesmos materiais, compostos por 16 frases experimentais contendo QU in-situ em ilhas sintáticas ${ }^{2}$ (por exemplo: você escreveu a mensagem que dizia o que / o que você escreveu a mensagem que dizia), 16 frases controle que continham QU in-situ, mas fora de ilhas, além de 40 frases distrativas. O quadro a seguir exemplifica alguns dos materiais usados nesse experimento:

\section{QUADRO 3 \\ Exemplos de materiais experimentais}

\section{Frases Experimentais:}

Relativa: Você escreveu a mensagem que dizia o quê?

Factiva: A sua filha lamenta que você não trouxe quem?

Adjuntiva: João chegou atrasado pedindo os formulários como?

Sujeito Sentencial: É obrigatório que a prova seja entregue até quando?

\section{Frases de Controle:}

No seu último aniversário, você ganhou o quê?

Aquela encomenda está sendo enviada para quem?

Ele conseguiu uma bolsa de estudos como?

Este relatório deve ser entregue até quando? 
As mesmas frases foram apresentadas a dois grupos de sujeitos: um grupo foi constituído por 24 alunos do curso de Letras que haviam terminado no momento do experimento um curso de Sintaxe, no qual haviam estudado, entre outros temas, as ilhas sintáticas, tendo considerado e analisado durante várias semanas períodos contendo diferentes tipos de construções com ilhas sintáticas. $\mathrm{O}$ outro grupo era constituído por 24 alunos de outros cursos universitários, que nunca haviam tido a sua atenção voltada para o fenômeno das ilhas sintáticas. Os resultados apresentaram os índices de julgamento indicados nos GRAF. 2 e 3, abaixo:

\section{GRÁFICO 2 \\ Índices de Aceitação para o Grupo 1}

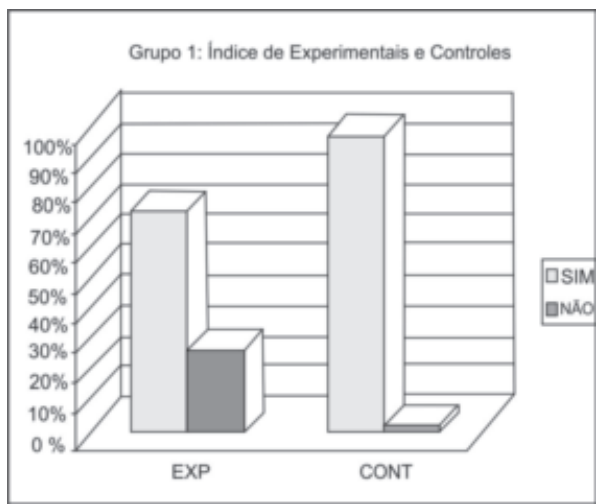




\section{GRÁFICO 3 \\ Índices de Aceitação para o Grupo 2}

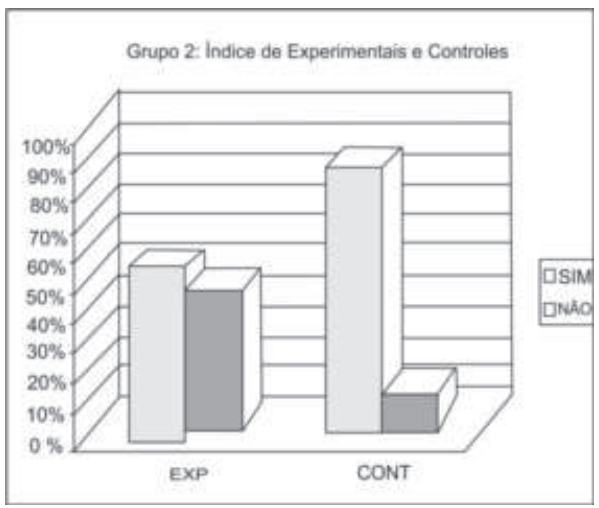

Como se vê nos gráficos., os sujeitos do grupo 1, que tinham consciência metalinguística sobre o fenômeno das ilhas sintáticas, tendo julgado anteriormente vários tipos de frases desse tipo, tenderam a recusar significativamente menos essas frases do que os sujeitos do grupo 2, que nunca haviam analisado tais frases. Com relação aos tempos médios de julgamento, os resultados obtidos também foram na mesma direção, havendo-se encontrado as seguintes médias:

\section{TABELA 3}

Médias dos tempos de resposta para as frases experimentais e controles do Grupo 1

\begin{tabular}{|c|c|c|c|c|}
\hline & EXP SIM & EXP NAO & CONT SIM & CONT NĀO \\
\hline Médias & $1075 \mathrm{~ms}$ & $1776 \mathrm{~ms}$ & $684.6 \mathrm{~ms}$ & $1122 \mathrm{~ms}$ \\
\hline
\end{tabular}

TABELA 4

Médias dos tempos de resposta para as frases experimentais e controles do Grupo 2

\begin{tabular}{|c|c|c|c|c|}
\hline & EXP SIM & EXP NAO & CONT SIM & CONT NĀO \\
\hline Médias & $1074 \mathrm{~ms}$ & $1331 \mathrm{~ms}$ & $734.3 \mathrm{~ms}$ & $1241 \mathrm{~ms}$ \\
\hline
\end{tabular}


Com base nas TAB. 3 e 4, podemos observar que, tanto no Grupo 1 quanto no Grupo 2, as frases experimentais aceitas exibiram latências de julgamento significativamente mais altas do que as frases de controle (Grupo 1: ANOVA: $\mathrm{F}=22.82$, $\mathrm{p}<0.0001$; Grupo 2: ANOVA: $\mathrm{F}=3.821$, $\mathrm{p}<0.0001)$. Na análise entre grupos, a diferença entre as médias de tempos para a negação das frases experimentais foi significativa, demonstrando que os sujeitos do Grupo 1, com consciência metalinguística, apresentaram maior relutância ao negar as frases contendo ilha sintática. As variáveis adjunto e argumento, bem como os diferentes tipos de ilha, não apresentaram diferenças significativas relevantes. Os resultados de ambos os grupos demonstraram aceitação em níveis altamente significativos para as frases de controle (sem Qu in-situ em ilhas sintáticas), demonstrando o efeito de ilha nas frases experimentais.

No entanto, enquanto o Grupo 2, que não tinha conhecimento metalinguístico, apresentou uma tendência não definida em relação às frases experimentais, o Grupo 1 demonstrou boa aceitabilidade dessas estruturas. Portanto, supomos que o conhecimento linguístico dos sujeitos participantes de uma pesquisa pode, de fato, vir a influenciar seus resultados. As médias dos tempos de resposta foram consistentes com os índices de julgamento: as frases de controle, além de bem aceitas, foram significativamente julgadas mais rapidamente do que as frases experimentais, como esperado anteriormente e apontando mais uma vez para o efeito de ilha nas frases experimentais.

O Grupo 1, com consciência metalinguística, não só aceitou mais as frases experimentais como apresentou tempos maiores para negar tais frases, demonstrando que, para os sujeitos com conhecimento prévio sobre as estruturas e questões estudadas na pesquisa, foi mais difícil negar as frases com $\mathrm{Qu}$ in-situ em ilhas sintáticas.

\section{Especificação e profundidade do processamento: efeitos diferenciados do input linguístico em tarefas on-line e off-line idênticas}

A importante questão da especificação e da profundidade do processamento foi explorada produtivamente por Christianson et al. (2001), Ferreira et al. (2002), estudos também replicados, em parte, por meio de testes de compreensão de frases equivalentes em português do Brasil por Ribeiro (2008), em estágio de pós-doutorado no âmbito do LAPEX / UFRJ. Testando experimentalmente estru- 
turas do tipo Late Closure, esses estudos concluem, de modo geral, que o processamento da linguagem muitas vezes é superficial (shallow), podendo resultar em representações semânticas imprecisas, incompatíveis com o valor de verdade do input. Conforme relatado em Ribeiro (2008), por exemplo, expostos a frases temporariamente ambíguas como "Enquanto o autor escrevia as anotações queimavam na lareira", os sujeitos, seguindo o princípio Late Closure, apõem preferencialmente o SN "anotações" como objeto do verbo "escrever", precisando, logo em seguida, ao encontrar o verbo "queimavam", proceder à reanálise da decisão default de analisar, inicialmente, o SN como objeto do verbo "escrever". Ao entrar no garden-path, os leitores deverão reanalisar o SN "anotações" como sujeito do verbo "queimavam". Quando, no entanto, perguntados, ao final da leitura, se "o autor escrevia as anotações", os sujeitos apresentam índice de respostas afirmativas significativamente alto, por comparação a controles, indicando que sua análise inicial da ambiguidade, ainda que inadequada e corrigida, pode ser persistente, influenciando a interpretação final da frase, que seria, então, no dizer de Ferreira, simplesmente good enough, ou seja, apenas boa o bastante para alguns propósitos. Em outras palavras, a interpretação seria rasa ou subespecificada ou ainda, no dizer de Phillips et al. (2011), falível.

\subsection{Good-enough com LC, mas não com $M^{3}$ ?}

\subsubsection{Good Enough com LC}

Ribeiro (2012) testa a Hipótese Good-Enough usando a técnica de rastreamento ocular. Ribeiro usa como materiais 16 conjuntos de frases tais como o conjunto exemplificado abaixo, que é distribuído em quadrado latino e apresentado randomicamente entre 16 frases distrativas, a 24 sujeitos, alunos de graduação da UEZO / RJ.

\section{QUADRO 4 \\ Exemplos de estrutura envolvendo o Princípio da Aposição Local}

EC: Enquanto o homem caçava os cervos correram para a mata fechada.

P: O homem caçava os cervos? SIM / NÃO

LC: Enquanto o homem caçava os cervos o faisão voou para longe.

P: O homem caçava os cervos? SIM / NÃO 
As 32 frases eram trazidas à tela, uma a uma, pelos sujeitos, por meio do pressionamento da barra de espaços, ali permanecendo por tempo fixo de $5 \mathrm{~s}$ no monitor de 17" de um Tobii $120 \mathrm{~Hz}$ Eye Tracker, em fonte do tipo Calibri (Corpo), tamanho 21. Ao fim do tempo de exposição de cada frase, elas eram substituídas pela pergunta interpretativa que lhe dizia respeito, a mesma tela mostrando, logo abaixo, em caixa alta, um SIM e um NÃO, que os sujeitos deviam escolher como resposta, fixando o olhar em um ou no outro.

Os resultados obtidos por Ribeiro indicaram que a duração média das primeiras fixações (First Fixation Duration - FFD) na região que resolve a ambiguidade de aposição sintática (por exemplo: a forma verbal correram, no exemplo EC, acima) foi de $335 \mathrm{~ms}$, enquanto que a região que lhe corresponde na condição não ambígua LC (o SN o faisão, no exemplo) foi de $268 \mathrm{~ms}$, produzindo diferença significativa $\left(\mathrm{t}(160)=2,969, \mathrm{p}=0,0034^{* *}\right)$, que é analisada pelo autor como indicativa do efeito garden-path. Ribeiro identifica ainda um percentual significativamente maior de fixações regressivas para a área ambígua da frase (no exemplo, o SN "os cervos”, ambíguo entre uma aposição como objeto direto do verbo da oração subordinada ou como sujeito da oração principal subsequente) no caso de EC (49\%) do que no caso de LC (21\%), novamente confirmando o efeito garden-path, que exige reanálise da região ambígua que o motivou. Entretanto, como aponta Ribeiro, o padrão de respostas às questões interpretativas mostra valores similares entre as condições LC e EC, recebendo tanto a condição EC quanto a LC índices significativamente maiores de acerto (SIM) do que de erro (NÃO), sustentando a Hipótese Good-Enough. O autor avalia que tais resultados confirmam os achados de Christianson et al. (2001), já verificados no PB, por Ribeiro (2008), concluindo que "as respostas off-line às perguntas após a leitura de EC sugerem que, muitas vezes, a análise inicial do input ambíguo persiste na memória de trabalho do leitor e interfere na interpretação final da frase, resultando em representações que não refletem o valor de verdade do input, imprecisas, ou, no dizer de Ferreira et al., simplesmente good-enough". Assim, temos aqui um caso bem documentado de falibilidade na interpretação de frases envolvendo o Princípio da Aposição Local (Late Closure). Como veremos a seguir, no entanto, falibilidade semelhante não se instancia em experimento de rastreamento ocular envolvendo construções ambíguas reguladas pelo Princípio da Aposição Mínima (Minimal Attachment - MA). 


\subsubsection{Reanálise completa em MA}

Reportamos, a seguir, o estudo de rastreamento ocular que analisa a leitura de frases do tipo MA. Maia et al. (2003) já havia estudado construções do tipo MA, em português, por meio de experimentos de leitura automonitorada. Um dos tipos de estrutura examinado naquele estudo é equivalente ao famoso exemplo de Tom Bever (1970) "The horse raced past the barn fell", em que a forma verbal "raced" é preferencialmente analisada inicialmente como passado simples, conduzindo a efeito garden-path ao chegar-se ao verbo "fell". A frase precisa, então, ser reanalisada sintaticamente, com a forma "raced" sendo identificada como particípio passado, modificador do núcleo "the horse", disponibilizando, assim a forma "fell" como o verbo principal da sentença. Em Português, um tipo equivalente de ambiguidade ocorre com formas tais como "oculta", "suspeita", "paga", etc., nas quais a forma verbal é ambígua entre a $3^{\mathrm{a}}$ pessoa do singular no presente e o particípio. Maia et al. (2003) desenvolvem um design que cruzava os traços [+humano] / [-humano], de um lado, com frases mínimas / não mínimas, de outro, entre outras condições, conforme exemplificado abaixo, com a divisão em quatro segmentos indicada por barras oblíquas:

\section{QUADRO 5}

\section{Exemplos das condições experimentais em Maia et alii (2003)}

+HM: A empresária / paga / com antecedência de um mês, / mas exige confiança.

+HN: A empresária /paga / com antecedência de um mês/ exige confiança.

-HM: A empresa / paga / com antecedência de um mês, / mas exige confiança.

-HN: A empresa / paga / com antecedência de um mês / exige confiança.

Os resultados indicaram que há uma preferência significativa pela estrutura mínima (verbo principal), conforme predito pelo Princípio da Aposição Mínima. A manipulação do traço [humano] NÃO afetou os tempos de leitura médios do segmento crítico. O segmento 4 foi lido mais rapidamente em $+\mathrm{HM}$ do que em $+\mathrm{HN}$ e também em $-\mathrm{HM}$ do que em $-\mathrm{HN}$, refletindo o efeito surpresa e a reanálise dos garden-paths. Por outro lado, notou-se que não há diferenças significativas quando se comparam os tempos de leitura médios das condições +HM e -HM ou os tempos de $+\mathrm{HN}$ e -HN, demonstrando a ausência de acesso semântico rápido pelo parser.

No presente estudo, usando a técnica de rastreamento ocular, prevíamos comprovar (1) o efeito garden-path já observado por nós no estudo de leitura au- 
tomonitorada; (2) o efeito de reanálise on-line da estrutura não mínima e (3) um efeito do tipo Good-enough na interpretação final da estrutura não mínima. Esta terceira previsão foi feita com base nos resultados obtidos por Ribeiro (2012) para as estruturas baseadas no Princípio da Aposição Local que, como relatado em 3.1.1, indicaram a persistência da análise incorreta, instanciando falibilidade do processo interpretativo de frases do tipo LC.

Apresentação do problema: De acordo com a TGP, a estruturação do input na compreensão de frase é imediata e incremental. Na fase inicial do processamento, quando há alternativa entre estruturação mínima e não mínima do input, o processador, seguindo o Princípio da Aposição Mínima, deve comprometer-se com a aposição mínima dos itens que compõem a oração ou sintagma que estiver sendo processado no momento. Esse compromisso máximo tem sido obtido na literatura para o inglês e para várias línguas, sendo exemplo clássico de acesso determinístico à informação estrutural no processamento on-line.

Em experimento de rastreamento ocular, Frazier e Rayner (1982) observaram que em frases Minimal Attachment (assim como em frases Late Closure) ocorre efeito garden-path (ou suspensão do processamento por "erro" na análise inicial da ambiguidade), sendo também processo de reanálise seletivo. No presente estudo de monitoramento de movimentos oculares, apresenta-se evidência de garden-path na leitura de frases do PB que apresentam ambiguidade entre "verbo na $3^{\mathrm{a}}$ pessoa do singular do presente do indicativo" e "adjetivo / particípio", analisadas com a adoção de estratégia equivalente, inclusive na seletividade de sua reanálise.

\section{QUADRO 6}

\section{Exemplos de estruturas envolvendo o Princípio da Aposição Mínima}

NMA: Mãe suspeita de assassinato do filho foge da delegacia.

P: Mãe suspeita de alguém? SIM / NÃO

MA: Mãe suspeita de assassinato do filho e foge da delegacia.

P: Mãe suspeita de alguém? SIM / NÃO

No processamento de NMA e MA, "suspeita", forma que conduz ao garden-path na primeira frase (NMA), mas não na segunda (MA), é tida como verbo na $3^{\text {a }}$ pessoa do singular presente do indicativo, cujo sujeito é "mãe", compondo-se, assim, inicialmente em ambos os casos, a estrutura mínima (ou com menos nós sintáticos) do input; por tal caminho, o leitor entra no garden-path na 
frase NMA e se vê na contingência de reanalisar a estrutura construída para interpretar, corretamente, NMA, a um custo maior para processá-la do que em MA.

Quanto à fase final do processamento, não se acham na literatura, estudos sobre processamento good-enough desse tipo de estrutura, como os que Ferreira et al. têm desenvolvido, utilizando estruturas cujo processamento é guiado por Late Closure, para mostrar que a reanálise não é um processo do tipo all-ornothing e, quando incompleta, pode resultar em representações semânticas imprecisas, incompatíveis com o valor de verdade do input. Ainda assim, no presente estudo, buscamos pela persistência, na memória de trabalho do leitor, da análise inicial do SN ambíguo que conduz o parser ao garden path, reanálise incompleta e, por decorrência, interpretação superficial do mesmo tipo de frase, conforme a Hipótese Good-enough.

Hipótese: os índices médios da Duração da Primeira Fixação (First Fixation Duration, FFD) sobre a região ambígua de NMA (entre a $3^{a}$ pessoa do singular do presente do indicativo do $\mathrm{V}$ e ADJ) e sua correspondente em MA ("suspeita" nos exemplos a seguir), não devem diferir significativamente, indicando, assim, que não há processamento paralelo da ambiguidade.

Quando apenas a aposição não mínima (como em NMA) serve à interpretação correta do input, a região que resolve a ambiguidade (forma verbal com duas sílabas) receberá maiores índices médios de First Fixation Duration (FFD) do que a região que lhe é correspondente (a conjunção "e" + V com duas sílabas em MA). A região ambígua de NMA (entre a $3^{\mathrm{a}}$ pessoa do singular do presente do indicativo do $\mathrm{V}$ e ADJ) deverá ser objeto de reanálise, observando-se sacadas regressivas diretamente para esta área.

No que concerne à Hipótese Good-enough, o número de movimentos sacádicos sobre SIM, resposta incorreta às pergunta após NMA, deverá ser mais elevado do que NÃO, e comparável ao número de sacadas sobre o SIM em resposta (correta) à pergunta após MA. Em termos das Áreas de Interesse (AOI) cujos tempos de fixação e número de movimentos sacádicos o software que serve ao eye tracker quantificou, a hipótese do estudo prediz: não haverá diferença significativa entre os índices médios de FFD sobre a AOI = "suspeita" em NMA e MA. A AOI = "foge" receberá índices médios de FFD mais elevados em NMA do que a AOI = "e foge" em MA. A AOI = "suspeita" receberá índices de sacadas e fixações regressivas maiores em NMA. Nas respostas às perguntas após NMA e após MA a $\mathrm{AOI}=\mathrm{SIM}$ receberá mais sacadas do que NÃO. 


\section{Sujeitos}

$\mathrm{N}=24$, de ambos os sexos, selecionados(as), ao acaso, entre alunos(as) dos cursos de formação de tecnólogos e de graduação plena da UEZO, todos naïves em relação ao objeto de estudo.

\section{Materiais}

16 frases-teste, em distribuição latin square, 8 em cada uma das condições, NMA e MA, seguidas, cada uma delas, da mesma pergunta, a responder com SIM ou NÃO, sondando a interpretação da forma ambígua entre $V$ na $3^{\mathrm{a}}$ pessoa do presente do indicativo e "ADJ / particípio". Intercaladas às frases-teste, os sujeitos leram também 16 frases distrativas, cada uma delas seguidas de uma pergunta sobre o seu conteúdo, a ser respondida com SIM ou NÃO.

\section{Procedimentos}

Cada uma das 32 frases foi mostrada durante tempo pré-fixado de 5 segundos no monitor de 17" de um Tobii $120 \mathrm{~Hz}$ Eye Tracker, centralizadas na tela, em fonte do tipo Calibri (Corpo), tamanho 21. Ao fim do tempo de exposição, as frases eram substituídas, cada uma, pela pergunta que lhe dizia respeito, a mesma tela mostrando, logo abaixo, em caixa alta, um SIM e um NÃO, que os sujeitos deviam escolher como resposta, fixando o olhar em um ou em outro. Antes de se desincumbir da tarefa, cada um dos sujeitos recebeu instruções e teve direito a uma breve sessão de treinamento. As sessões de experimentação foram realizadas nas dependências da UEZO.

\section{Resultados}

As FFD médias sobre a região ambígua de NMA ("suspeita") e a que lhe é correspondente em MA, que aparecem no GRAF. 4 (Colunas 1), abaixo, não diferiram significativamente $(\mathrm{t}(158)=1,79, p=0,07 \mathrm{~ms})$, confirmando a hipótese de que não houve processamento paralelo da ambiguidade. 


\section{GRÁFICO 4}

Colunas 1: FFD médias sobre a região ambígua em

NMA e a que the corresponde em MA

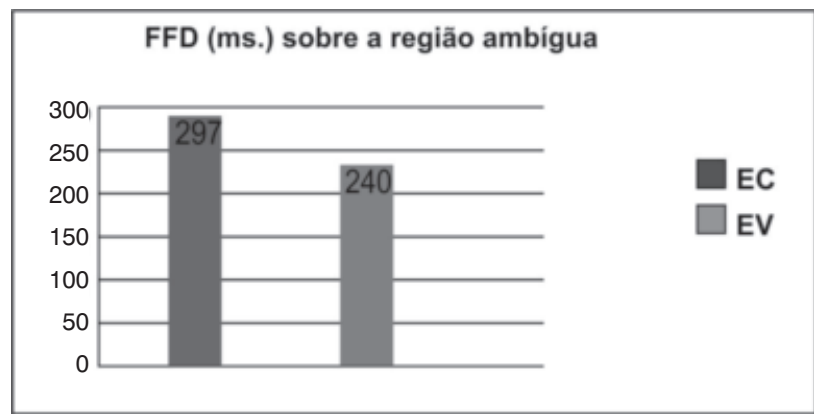

Por outro lado, vêem-se no GRAF. 5 (Colunas 2), a seguir, os valores determinantes da diferença significativa $(\mathrm{t}(176)=5,725, p=0,0001 * * *)$, entre as médias da Duração da Primeira Fixação (FFD) sobre a região que resolve a ambiguidade em NMA (363ms.) e a que lhe corresponde em MA (243ms.), mostrando que o parser foi malsucedido na análise inicial de EC e levado ao garden-path. Tal assimetria, replicando os achados de Frazier e Rayner (1982), só se explica pela adoção, no parsing, da estratégia de Aposição Mínima (Minimal Attachment) da forma ambígua de EC, feliz na análise de MA.

\section{GRÁFICO 5}

Colunas 2: FFD médias sobre a região que resolve a ambiguidade de NMA e a sua correspondente em MA

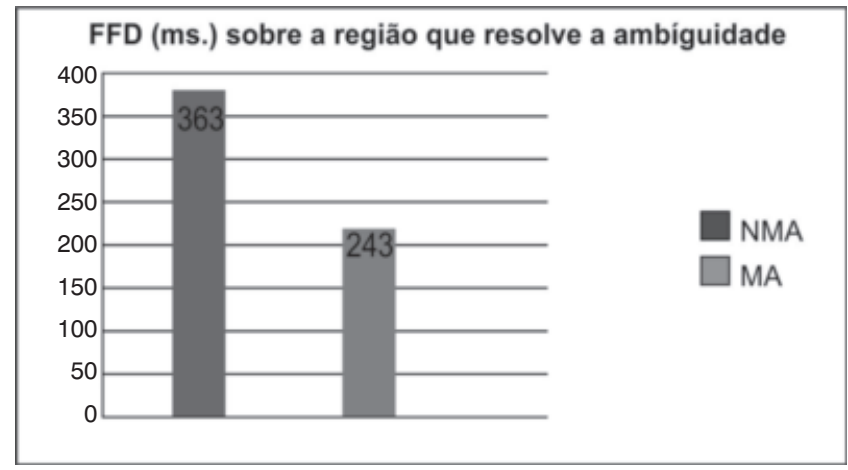


As diversas métricas oferecidas pelo software acoplado ao eye tracker utilizado podem ser visualizadas em mapas de calor (heatmaps) que retratam, em uma escala de cor, dos tons esverdeados, passando pelo amarelo e pelos tons alaranjados, até chegar ao vermelho, a duração da fixação, (primeira fixação e fixação total) e o número de movimentos sacádicos sobre as Áreas de Interesse assinaladas nos estímulos, dos menores aos maiores valores atribuídos a essas métricas pelas operações de quantificação geradas pelo sistema. Graças a esse recurso, pode-se ver ilustrada, no Mapa de Calor (heatmap) 1, a seguir, a convergência entre os índices de "calor" na primeira passagem do olhar (first-pass) sobre "suspeita" em NMA e MA, demonstrando que, àquela altura, não houve processamento paralelo da ambiguidade, conforme propugna a TGP e de acordo com a hipótese testada.

\section{FIGURA 1}

Mapa de Calor heatmap) 1: FFD médias sobre a região ambígua e a que resolve a ambiguidade de NMA e os seus equivalentes em MA

\section{FFD (ms.) sobre a região ambígua e sobre a que resolve a ambiguidade.}

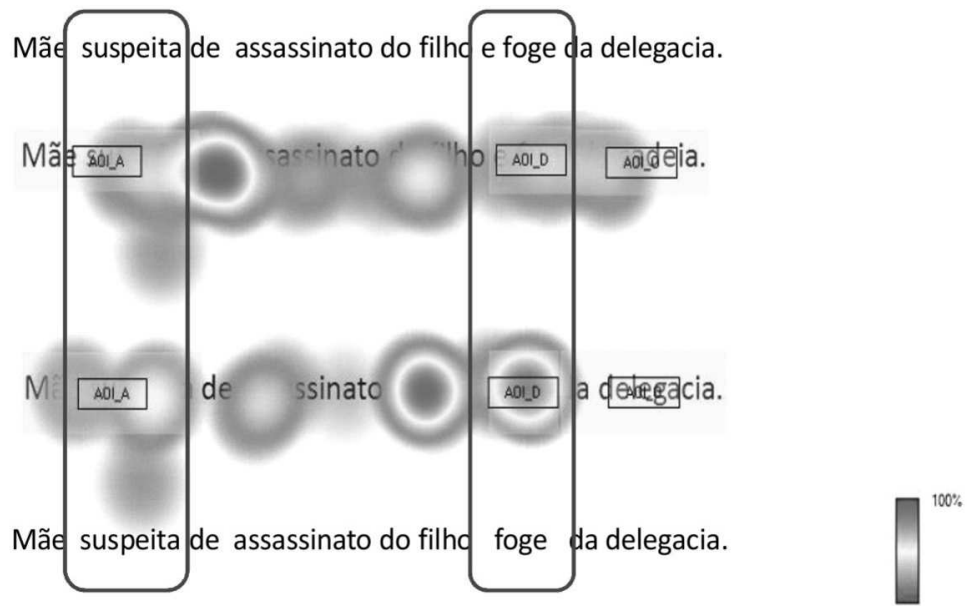


No mesmo Mapa de Calor (heatmap) 1, nota-se a mancha avermelhada sobre a região que resolve a ambiguidade de NMA - "foge" - refletindo a média da Duração da Primeira Fixação (FFD), em nítido contraste com a mancha sobre "e foge", esverdeada, que recebeu FFD média significativamente inferior. O inesperado de "foge" sinaliza que "algo deu errado", e o parser perde-se no gardenpath "à procura" de um SUJ para o verbo, pois o SN "mãe" já se acha comprometido com o verbo "suspeita", na estrutura anteriormente construída. De fato, "foge" é o item que resolve a ambiguidade, ao desencadear a reanálise da estrutura: "suspeita" passa a ADJ / particípio, introduzindo uma cláusula relativa reduzida (em que se omitem o pronome relativo e o verbo de ligação, em lugar de "que é suspeita"), e, sendo assim, o SN "mãe" fica liberado para ocupar a posição de SUJ de "foge", verbo da (nova) oração principal.

Contudo, se a reanálise que serve à interpretação correta de $\mathrm{N}$ deve partir da busca de um sujeito para o verbo "foge", o parser pode realizá-la de três maneiras: 1) retornando ao início da frase para reestruturá-la completamente, 2) backtracking, item a item até se deparar com aquele que resolve o problema, ou 3) regressando, de maneira seletiva, ao SN ambíguo, "suspeita", e realocá-lo na posição que permita a continuidade do processamento da frase. Ainda ratificando as observações de Rayner e Frazier (1982) entre os registros de regressões do olhar durante a leitura de NMA a partir do item que assinalava que o parser se perdera no garden-path, predominaram aquelas que se dirigiram, de maneira seletiva, diretamente à forma ambígua "suspeita" $\left(59,38 \% ;\left(\mathrm{x}^{2}(1)=18,9, p<\right.\right.$ 0,0001***)), conforme o GRAF. 6 (Colunas 3) (abaixo).

\section{GRÁFICO 6}

Colunas 3: regressões do olhar durante a leitura de NMA, a partir do item que assinalava que o parser se perdera no garden-path, e de MA

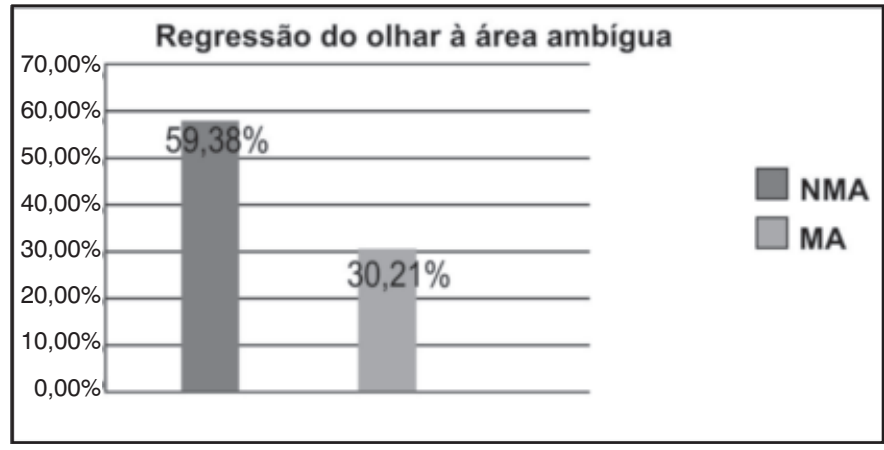


Entretanto, a diferença significativa $(\mathrm{t}(12)=2,61, \mathrm{p}=0,02 *)$ entre os índices de Duração da Fixação $(F D=1.537 \mathrm{~ms})$ sobre a resposta NÃO, correta, e de Duração da Fixação $(F D=666 \mathrm{~ms})$ sobre a resposta SIM, incorreta, à pergunta após $N M A$ (ao contrário do que se mostrou, nos resultados do Experimento 1A, em relação ao Princípio da Aposição Local e a Hipótese Good-Enough) indicam que, aqui, o sujeitos saíram do garden-path a que foram levados durante a leitura de frases cujo parsing segue o Princípio da Aposição Mínima, graças à reanálise completa do input, mais do que recorreram a interpretações good-enough, conforme o GRAF. 7 (Colunas 4), a seguir.

\section{GRÁFICO 7}

Colunas 4: FD médio nas respostas NÃO, corretas, indicando reanálise do input após NMA; e SIM, corretas, após MA

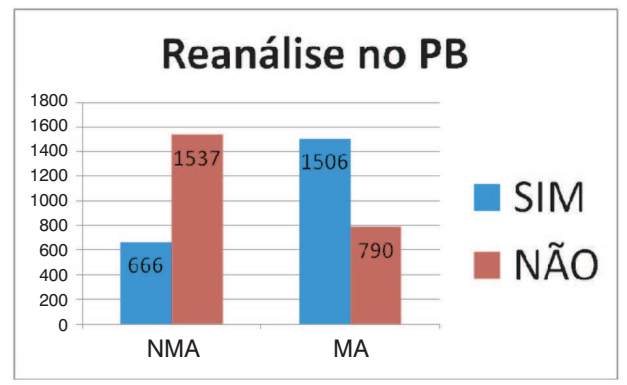

Desde que as respostas foram dadas mediante a fixação do olhar, mostra-se, no Mapa de Calor (heatmap) 2, abaixo, um caso exemplar de contraste entre a mancha sobre o SIM, resposta correta a MA (não ambígua), na parte superior da imagem, e, abaixo, o NÃO que reflete a reanálise de NMA. 


\section{FIGURA 2}

Mapa de Calor (heatmap) 2: FD na resposta SIM (correta) após MA; e NÃO (correta) após NMA, refletindo a reanálise

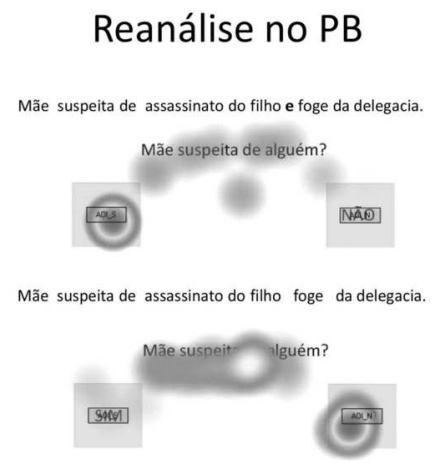

Discussão

Os resultados desse experimento, bem como o do experimento apresentado em 3.1, também ratificam os resultados de Frazier e Rayner (1982) e confirmam as predições da TGP. A Duração da Primeira Fixação, ou FFD, sobre a região ambígua dos estímulos, NMA e MA não diferiu significativamente, indicando que não houve processamento paralelo da ambiguidade de NMA. Observou-se diferença significativa entre a FFD sobre a região que resolve a ambiguidade de NMA, e a correspondente em MA, sustentando a hipótese de processamento serial, baseado, inicialmente, apenas na informação sintática do input, seguindo o Princípio da Aposição Mínima, o que, durante a leitura de NMA, levou o parser ao garden-path. $\mathrm{E}$ a reanálise se deu, preferencialmente, por movimentos regressivos seletivamente direcionados à região ambígua de NMA.

Por outro lado, não foi possível confirmar os achados de Christianson et al. (2001), já verificados no PB, por Ribeiro (op. cit.), tendo em vista as respostas off-line às perguntas após a leitura de NMA, que sugerem que, na maioria das ocasiões, a reanálise foi bem sucedida. Na interpretação do exemplo "Mãe suspeita de assassinato do filho foge da delegacia" provavelmente (e aqui só é lícito especular, porque não se controlou a variável "plausibilidade", cuja interferência já foi observada por Christianson et al.(2001) e Ribeiro (2008), favorecendo o processamento good-enough de frases cujo parsing segue Late Closure) a im- 
plausibilidade do cenário "mãe suspeita" (análise inicial) e "mãe foge da delegacia" (reanálise) provavelmente, repito, força a sua rejeição, ao passo que a concomitância de "o homem caça os cervos" (análise inicial) e "os cervos correm para a floresta" (reanálise) convidariam à sua aceitação. Mais do que isso, por ora, a falta, na literatura, de estudos que associem o efeito garden-path decorrente do parsing guiado pelo Princípio da Aposição Mínima e a Hipótese Good-enough impede de afirmar, sugerindo que sejam realizados, em caráter inédito no PB.

A questão que, naturalmente, se coloca, então, seria a de saber-se porque a reanálise é falível em relação às estruturas de Aposição Local, mas infalível em relação às estruturas de Aposição Mínima. A resposta a essa pergunta, como já indicado acima, depende de maior controle da plausibilidade dos cenários, nos dois casos. Entretanto, uma linha de investigação a ser perseguida em trabalhos futuros, além do controle estrito da plausibilidade, deverá focalizar a aferição da intensidade do efeito garden-path. Note-se que, avaliando-se o tamanho do garden-path obtido na medida FFD para as frases de Aposição Mínima $(\mathrm{t}(176)=5,725$, $\left.p=0,0001^{* * *}\right)$, observa-se diferença maior do que o que se obteve na mesma medida para as frases de Aposição Local $\left(\mathrm{t}(160)=2,969, \mathrm{p}=0,0034^{* *}\right)$. Especulamos, nesse sentido, como hipótese a ser testada em futuros trabalhos, que um efeito garden-path mais intenso poderia ocasionar uma interpretação final menos falível, facilitando o diagnóstico e a recuperação do garden-path, na linha do que é proposto no quadro teórico de Fodor e Inoue (1994), já mencionado na seção 2.2 do presente trabalho. Segundo este quadro, a recuperação de um garden-path seria função da dificuldade do diagnóstico. Nesse caso, o garden-path de maior intensidade observado em MA teria sido, de fato, facilitador da reanálise que se observa em relação a essas estruturas, mas não no caso das estruturas LC, em que o garden-path menos intenso permitiria a persistência da análise inicial incorreta.

\section{Considerações finais}

Resenhamos no presente artigo estudos realizados no âmbito do Laboratório de Psicolinguística Experimental (LAPEX / UFRJ) e apresentamos um estudo inédito de rastreamento ocular de estruturas de Aposição Mínima, realizado em conjunto com Antonio Ribeiro na UEZO / RJ, com o objetivo de trazer à luz questões relacionadas à aferição on-line e off-line dos processos linguísticos e da profundidade do processamento, que pode se mostrar mais ou menos profundo e mesmo falível em certas circunstâncias relacionadas às técnicas de aferição, aos 
grupos de sujeitos experimentais ou mesmo em decorrência da natureza do input linguístico.

Observe-se que o estudo sistemático, por meio de metodologias cronométricas, dos processos de especificação da informação sintática, semântica e pragmática, em diferentes momentos, durante o curso temporal da compreensão de diferentes construções linguísticas, bem como o controle de fatores relacionados aos grupos de sujeito, que podem interferir na profundidade do processamento, pode ser crucial para que se possa discutir adequadamente diferentes arquiteturas cognitivas, colocando em exame mais preciso, tanto a relação competência / desempenho quanto os modelos de processamento a que aludimos acima, a saber, modelos de processamento serial e modelos de processamento em paralelo. A fundamentação desses distintos tipos de modelos tem como questão central, exatamente, tanto a natureza das informações usadas pelo parser para guiar suas decisões de processamento quanto o momento de acesso a tais informações. Trata-se de determinar se o parser é estritamente sintático e serial em sua análise inicial ou se já acessa rapidamente, em paralelo, informações de natureza semântica, prosódica e pragmática a tempo de influenciar a análise sintática. Nesse sentido, determinar com maior precisão as condições do conhecimento subespecificado no acesso lexical, no processamento sintático e no processamento semântico é fundamental para avançarmos nosso entendimento de questões relacionadas à representação e ao processamento, permitindo a proposição de arquiteturas linguísticas e psicolinguísticas adequadas.

\section{Notas}

${ }^{1}$ Clifton, Speer e Abney (1991), utilizando técnicas de leitura automonitorada e de rastreamento ocular, demonstram preferência mais rápida do parser por SPs apostos ao verbo do que por SPs apostos ao nome, em inglês, conforme predito pelo princípio da Aposição Mínima. Por outro lado, o estudo só encontrou evidências para distinção entre SPs adjuntos e argumentos na região seguinte à do $\mathrm{SP}$, concluindo contra o acesso lexical rápido pelo parser sintático.

${ }^{2}$ Em trabalho clássico na literatura gerativa, Ross (1967) analisou uma série de construções sintáticas que funcionavam como barreiras ou ilhas para o movimento de extração de palavras Qu nas línguas. Posteriormente, Chomsky (1977) reúne os vários tipos de ilha que Ross propôs (orações relativas, factivas, adverbiais, sujeitos sentenciais, etc.) em um 
princípio único: a Condição de Subjacência, que propõe a generalização de que o movimento sintático não pode atravessar mais do que uma barreira, definindo-se os nós sintáticos SF (sintagma flexional) e SN (sintagma nominal) como barreiras. Rizzi (1982) propõe a parametrização da Condição de Subjacência, indicando que em algumas línguas as barreiras relevantes para o movimento de Qu sejam SC (sintagma complementizador) e SN.

${ }^{3}$ Os dois estudos de rastreamento ocular reportados nesta seção foram desenvolvidos em conjunto por Antonio Ribeiro e Marcus Maia, no equipamento Tobii $120 \mathrm{~Hz}$, obtido pelo primeiro pesquisador para a UEZO / RJ. A pesquisa sobre as construções envolvendo o Princípio da Aposição Local (Late Closure) foi apresentada por Ribeiro durante o XVI Congreso Internacional de la ALFAL, na Espanha, em 2011, e publicada na Revista Virtual de Estudos da Linguagem - ReVEL, em 2012. A pesquisa sobre as construções envolvendo o Princípio da Aposição Mínima (Minimal Attachment) foi originalmente apresentada por Marcus Maia durante o XVI Congreso Internacional de la ALFAL, na Espanha, em 2011, mas ainda não havia sido publicada até o presente momento. Ambos os estudos foram originalmente reportados no manuscrito RELATÓRIO DAS ATIVIDADES DE BOLSISTA DE PÓS-DOUTORADO (PDR), encaminhado à FAPERJ por Antonio Ribeiro, por ocasião do encerramento de seu estágio de pós-doutorado no LAPEX, como bolsista da FAPERJ, sob a supervisão de Marcus Maia, em julho de 2011.

\section{Referências}

BARILE, Wendy; MAIA, Marcus. Aspectos prosódicos do Qu in-situ no português brasileiro. ReVEL. v. 6, n. 11, Ago. 2008. ISSN 1678-8931 [www.revel.inf.br]. 2008.

CHOMSKY, Noam. On Wh-movement. In: CULICOVER, P; WASOW, Thomas; AKMAJIAN, Adrian. Formal Syntax. New York: Academic Press. 1977.

CHOMSKY, N. The Minimalist Program. Cambridge, MIT Press, 1995.

CLIFTON, C. Jr.; SPEER, S. R.; ABNEY, S. P. Parsing arguments: Phrase structure and argument structure as determinants of initial parsing decisions. Journal of Memory and Language, n. 30, p. 251-271, 1991.

COWART, Wayne. Experimental syntax: Applying objective methods to sentence judgments. Thousand Oaks: Sage Publications, 1997.

CHRISTIANSON, K.; HOLLINGWORTH, A.; HALLIWELL, J.; FERREIRA, F. Thematic roles assigned along the garden-path linger. Cognitive Psychology, n. 42, p. 368407, 2001.

FEATHERSTON, S. Data in Generative Grammar; the carrot and the stick. Theoretical Linguistics, n. 33 (3), p.269-318. 2007.

FERREIRA, F.; BAILEY, K.; FERRARO, V. Good-enough representations in language 
comprehension. Current Directions in Psychological Science, n. 11, p. 11-5, 2002. FODOR, J. D.; INOUE, A. The Diagnosis and Cure of Garden Paths. Journal of Psycholinguistic Research, v. 23, n.5, p. 407-434, 1994.

FRAZIER, L. On comprehending sentences: Syntactic parsing strategies. PhD Thesis Dissertation. University of Connecticut, Indiana University Linguistics Club, 1979.

FRAZIER, L.; J. D. FODOR. The Sausage Machine: A new two-stage parsing model. Cognition, n. 6, p. 1-34, 1978.

FRAZIER, L.; K. RAYNER. Making and correcting errors during sentence comprehension: Eye movements in the analysis of structurally ambiguous sentences. Cognitive Psychology, v. 14, p. 178-210, 1982.

GARDNER, H. The mind's new science: A history of the cognitive revolution. New York: Basic Books, 1985.

GIBSON, E.; FEDORENKO, E. Weak quantitative standards in linguistics research. Trends in Cognitive Sciences, v. 14, n. 6, p. 233-234, 2010.

HALLE, M.; MARANTZ, A. . Distributed Morphology and the Pieces of Inflection. In: HALE, K. E KEYSER, S. J. (Ed.). The View from Building 20. Cambridge, Massachusetts: MIT Press, 1993. p. 111-176.

HILL, A. A. Grammaticality. Word, n. 17, p. 1-10, 1961.

KITAGAWA, Yoshihisa; FODOR, Janet Dean. Prosodic influence on syntactic judgments. In: FANSELOW, Gisbert et alii. Gradience in Grammar: Generative Perspectives. Oxford: Oxford University Press, 2006.

LABOV, W. When intuitions fail. In: MCNAIR, L.; SINGER, K.; DOLBRIN, L.; AUCON, M. (Eds.). Papers from the Parasession on Theory and Data in Linguistics. Chicago Linguistic Society, n. 32, p. 77-106, 1996.

MACDONALD, M. C.; PEARLMUTTER, N.J.; SEIDENBERG, M.S. The Lexical nature of syntactic ambiguity resolution. Psychological Review, 101, p. 676-703, 1994.

MAIA, M.; ALCÂNTARA, S.; BUARQUE, S.; FARIA, F. O Processamento de concatenações sintáticas em três tipos de estruturas frasais ambíguas em português. Fórum Linguístico, v. 4, n. 1, p. 13-53, 2003.

MAIA, M. A. R. Efeitos do status argumental e de segmentação no processamento de sintagmas preposicionais em português brasileiro. Cadernos de Estudos Lingüísticos (UNICAMP), v. 50, p. 13-28, 2008.

MAIA, M. A. R. Rastreamento Ocular de Sintagmas Preposicionais Ambíguos em Português. $A B R A L I N$, v. 9, p. 11-36, 2010

MAIA, M. A. R.; FINGER, Ingrid. Processamento da Linguagem. 1a. ed. Pelotas, RS: EDUCAT, 2005.

PHILLIPS, C. Should we impeach armchair linguists? In: IWASAKI, S., HOJI, H., CLANCY, P.; SOHN, S.-O. (Eds.), Japanese / Korean Linguistics 17. Stanford, CA: CSLI Publications, 2009.

PHILLIPS, C.; WAGERS, M. W.; LAU, E. F. Grammatical illusions and selective fallibility in real-time language comprehension. In: RUNNER, J. (Ed.). Experiments at the 
Interfaces, Syntax \& Semantics, v. 37, p. 153-186, Bingley, UK: Emerald Publications, 2011.

RIBEIRO, Antonio J. C. A abordagem Good-Enough e o processamento de frases do português do Brasil. Veredas (UFJF On-line), v. 12, n. 2, p. 62-75, 2008.

RIBEIRO, Antonio João Carvalho. Late Closure e Good-Enough no processamento de frases garden-path do português do Brasil: evidências de eyetracking. ReVEL, v. 10, n. 18, 2012. [www.revel.inf.br].

RIZZI, Luigi. Violations of the wh-island constraint and the subjacency condition. In: RIZZI, Luigi. Issues in Italian Syntax. Dordrecht: Foris, 1982.

ROSS, John Robert. Constraints on variables in syntax. Ph.D Thesis dissertation. MIT, Bloomington, Indiana: University Linguistics Club Publication, 1967.SANFORD, A. J. \& STURT, P. Depth of processing in language comprehension: Not noticing the evidence. Trends in Cognitive Science, 6, 382-386, 2002.

SCHÜTZE, Carson T. The Empirical Base of Linguistics: Grammaticality Judgments and Linguistic Methodology. Chicago: University Of Chicago Press, 1996.

SNYDER, W. An experimental investigation of syntactic satiation effects, LI 31, p. 575582, 2000.TRUESWELL, J. C.; TANENHAUS, M. K. \& GARNSEY, S. M. Semantic influences on parsing: Use of thematic role information in syntatic ambiguity resolution. Journal of Memory and Language, v.33, p. 285-318, 1994.

TRUESWELL, J. C., TANENHAUS, M. K. \& KELLO, C. Verb-specific constraints in sentence processing: Separating effects of lexical preference from garden-paths. Journal of Experimental Psychology: Learning, Memory and Cognition, 19(3), 528-553, 1993. 
